\title{
Two cases of asbestosis and one case of rounded atelectasis due to non-occupational asbestos exposure
}

\author{
S.M. Candura, A. Binarelli, G. Ragno, F. Scafa
}

ABSTRACT: Two cases of asbestosis and one case of rounded atelectasis due to non-occupational asbestos exposure. S.M. Candura, A. Binarelli, G. Ragno, F. Scafa.

Asbestos is a well-known cause of several neoplastic (malignant mesothelioma, lung cancer) and non-neoplastic (asbestosis, pleuropathies) occupational diseases. Lower-level exposure in the general environment may induce pleural plaques and thickenings, and is associated with an increased mesothelioma risk. We present two patients (a 68-year-old man and a 72-year-old woman) who developed asbestosis (in association with pleural plaques and calcifications), and a 78-year-old man who developed rounded atelectasis (with pleural plaques and benign effusion), after living for several decades in the proximity of large Italian asbestos-cement plant. None of them had been exposed to asbestos occupationally. Besides living in a contaminated area, the woman used to clean the work clothes of her brother, who was employed in the local asbestos factory. The three cases indicate that non-neoplastic, long-latency asbestos-related diseases which are usually observed as a consequence of occupational exposures, may rarely develop in subjects living in contaminated geographical sites and buildings. These unusual environmental diseases raise the diagnostic problem of differentiating them from other, more common respiratory illnesses, and impose the duties of patient notification, assessment and follow-up, to assess the possibility of progression of disease and increased neoplastic risk.

Monaldi Arch Chest Dis 2008; 69: 1, 35-38.

Keywords: Pneumoconiosis, Folded lung, Pleuropathy, Environmental disease, Radiodiagnostics, Bronchoalveolar lavage.

Occupational Medicine Unit, University of Pavia and Salvatore Maugeri Foundation, Work and Rehabilitation, IRCCS, Scientific Institute of Pavia, Italy.

Correspondence: Prof. Stefano M. Candura, UO di Medicina del Lavoro, Fondazione Salvatore Maugeri, Via Maugeri 10, 27100 Pavia, Italy; e-mail: stefano.candura@fsm.it

\section{Introduction}

Asbestos continues to represent a major public health concern despite the progressive introduction of restrictive laws concerning its extraction, import/export, and use by most industrialised countries [1-3]. Inhalation of asbestos fibres may cause asbestosis (interstitial lung fibrosis), benign pleural abnormalities (diffuse thickening, plaques, calcification, pleural effusion, chronic pleural pain, rounded atelectasis), and neoplastic diseases (lung cancer and malignant mesotheliomas), with the risk proportional to the duration and intensity of exposure [1-5]. The highest exposure levels are usually reached in an occupational setting. Additionally, the general population may be exposed to asbestos (from natural or man-made sources) by living in contaminated geographical areas or buildings $[2,5]$.

Since the asbestos concentrations encountered at home or in the general environment are usually low, non-occupational exposure has been mainly associated with elevated mesothelioma risk, for which a safety threshold is apparently lacking
$[1,2,4]$, and pleural plaques and/or thickenings, for which the relationship between dose and response is weaker than for parenchymal asbestosis [6-8]. Here we report two unusual cases of asbestosis and one exceptional case of Blesovsky's syndrome (rounded atelectasis), due to asbestos inhalation in the living environment.

\section{Case reports}

The first patient is a 68-year-old man (former smoker), who was hospitalised for rehabilitation after surgery (triple aortocoronary by-pass for ischemic cardiopathy), presenting exertional dyspnea. No thoracic pain or electrocardiographic signs of ischemia were present. Chest examination revealed inexpansibility of the left pulmonary base, and bilateral diffuse crackles. Chest radiography (figure 1), radioscopy and high resolution computed tomography (HRCT) demonstrated post-operative paralysis of the left emidiaphragm, millimetric irregular opacities to both lungs, diffuse interstitial fibrosis, calcified plaques on the diaphragmatic pleura, and pleural thickenings. Spirometry showed 


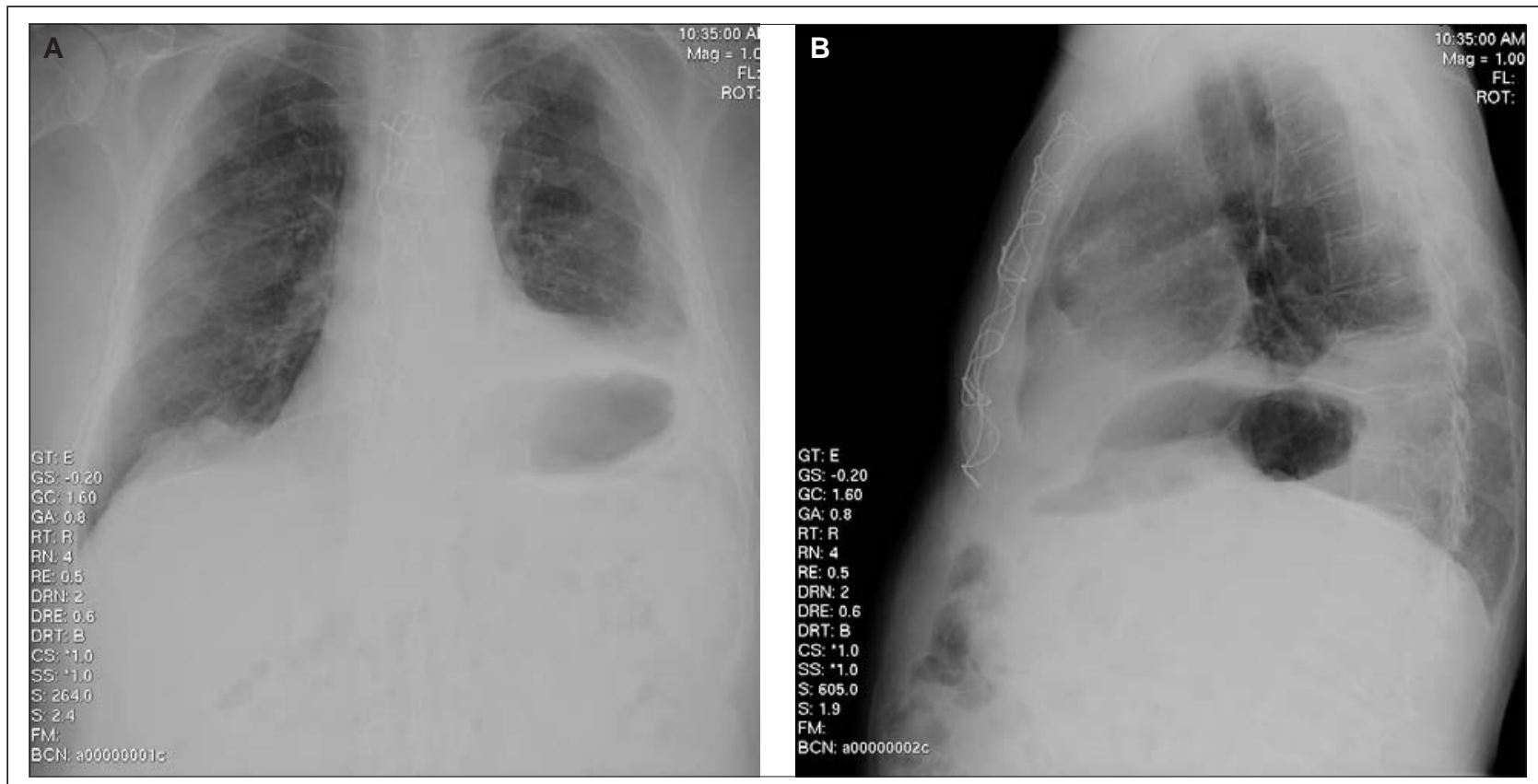

Fig. 1. - Chest radiographs (A: frontal projection; B: lateral projection) showing diffuse interstitial changes, calcified plaques on the diaphragmatic pleura, and pleural thickenings. Pleural alterations are particularly evident on the left side. Elevation of the left emidiaphragm with homolateral basal pleural effusion, and sternotomic surgical sutures are also evident. The cardiac shape is not correctly valuable. ILO classification: s $2 / 2$ pl plc co.

a restrictive pattern with a $25 \%$ decrease in the forced vital capacity (FVC). Bronchoscopy with bronchial brushing and bronchoalveolar lavage (BAL) gave normal findings.

Born in Sicily, the subject had been living since the age of 15 in the town of Casale Monferrato (North West Italy), $6 \mathrm{~km}$ from the largest asbestos-cement Italian factory. This plant operated from 1907 to 1986, producing high pressure pipes and several other asbestos-containing articles, using both crocidolite and chrysotile, and employing up to 1,500 workers [9]. In 1981, the company reported the utilisation of 15,000 metric tonnes of asbestos, $10 \%$ of which was crocidolite. The factory was about $1,300 \mathrm{~m}$ from the town centre, and 250 $\mathrm{m}$ from the closest residential areas. The inhabited area was downwind from the industry in respect to dominant winds. Additional asbestos pollution derived from the large local use of asbestos products; in 1990, for example, asbestos-cement roofs amounted to $500,000 \mathrm{~m}^{2}$ in a town of about 40,000 inhabitants [10]. The patient himself lived in an asbestos-covered house. Careful occupational anamnesis was negative for asbestos exposure.

Final diagnosis was asbestosis with benign pleural disease due to neighbourhood asbestos exposure. ILO radiologic classification [11] was: s (thin irregular opacities), 2/2 (moderate profusion), pl (pleural thickening), plc (pleural calcifications), co (abnormal cardiac shape).

The second patient is a 72-year-old woman (obese and heavy smoker) with chronic obstructive pulmonary disease (COPD), who came under observation for worsening of the respiratory symptomatology (productive cough, exertional dyspnea, signs of bronchial obstruction at chest examination). Chest X-ray (figure 2) and HRCT revealed thin irregular opacities to the bases of both lungs, and diaphragmatic pleural plaques with microcal- cifications. Spirometry showed a mixed, obstructive/restrictive pattern. Arterial blood gas analysis evidenced marked hypoxemia $\left(\mathrm{pO}_{2}: 50 \mathrm{mmHg}\right)$ and mild hypercapnia $\left(\mathrm{pCO}_{2}: 47 \mathrm{mmHg}\right)$. An asbestos fibre was retrieved by BAL (figure 3 ).

Since the age of 25 , the patient had been living in Broni (a small town near Pavia, North Italy), where a large industry produced asbestos-cement from 1932 to 1993. The plant was at about $600 \mathrm{~m}$ from the town centre [12]. She was not exposed to asbestos occupationally, but lived with her brother, who was employed in the local asbestos factory for 20 years: the patient used to brush and wash his work clothes.

The following diagnosis was formulated: asbestosis and pleural plaques due to neighbourhood

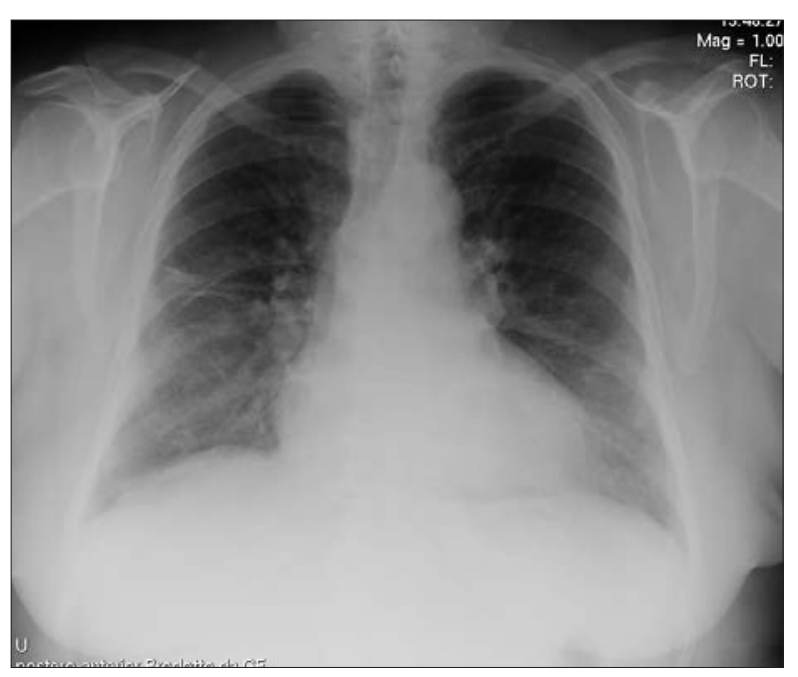

Fig. 2. - Chest radiograph (frontal projection) demonstrating interstitiopathy, particularly evident at the inferior pulmonary lobes, and plaques with microcalcifications on the diaphragmatic pleura obliterating the costophrenic angles. The cardiac shape is enlarged. ILO classification: s $2 / 2$ plc co cp. 


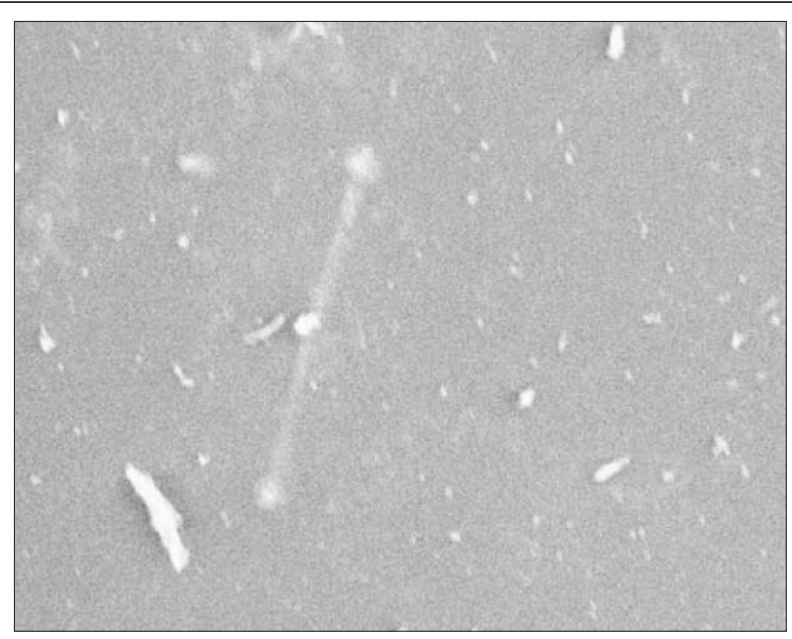

Fig. 3. - Microphoto $(5000 \mathrm{x})$ of particulate from bronchoalveolar lavage collected on nitrocellulose filter, showing an uncoated asbestos fibre.

and domestic exposure; ILO classification: s 2/2 plc co cp (chronic pneumopathy).

The third patient is a 78-year-old man (former smoker), who was admitted to hospital for exertional dyspnea. Examination revealed dullness and decreased breath sound over the left pulmonary base. Chest imaging (figure 4) showed left pleural effusion with peripheral round atelectasis, and bilateral pleural plaques. Evacuative thoracentesis was performed: the fluid was clear, and cytology did not detect abnormal cells; microbiological analysis was negative. The pleural effusion did not reform. Occupational history was negative for asbestos inhalation. Since the patient had always lived in Casale Monferrato, and in the absence of other possible causes, the pleuropathy were attributed to neighbourhood asbestos exposure.

\section{Discussion}

Non-occupational asbestosis in association with benign pleural lesions was diagnosed in two patients. The first came from Casale Monferrato, where the largest Italian asbestos-cement industry was active until 1986, causing a substantial increase in the incidence of pleural mesothelioma among the workers employed in the factory [9], their wives [13-15], and in the general population without occupational or domestic exposure [16]. In the same area, asbestosis was diagnosed by histological examination of autoptic lung samples from two women with neighbourhood exposure. Both had lived in Casale Monferrato for over 50 years; one was a teacher who had been employed for 12 years in a school close $(250 \mathrm{~m})$ to the factory [16].

The second case was from Broni, another Italian town that hosted a large asbestos-cement factory (until 1993), where an increased mesothelioma incidence among the general population has been reported [12]. Besides living in Broni, the woman used to clean her brother's work clothes, a duty that releases considerable amounts of asbestos fibres [6, 17]. In this patient, one element that helped us formulate the diagnosis was the retrieval of an as-

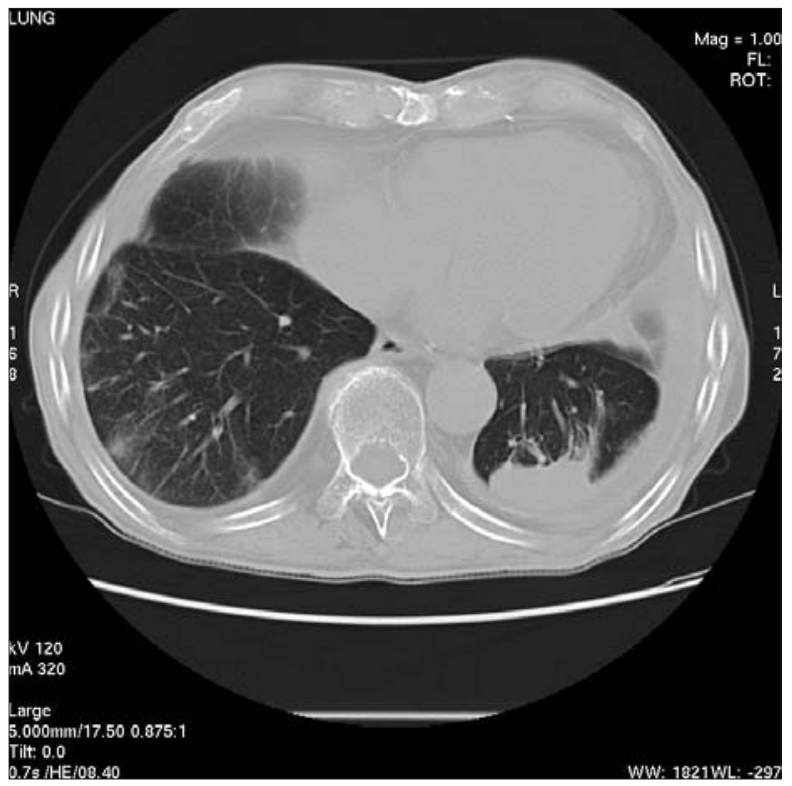

Fig. 4. - Chest computed tomography: postero-lateral pleural effusion on the left side, delimitating a peripheral parenchimal area of consolidation with distortion of vasal branches (rounded atelectasis).

bestos fibre by BAL (figure 3), a rare finding in people not occupationally exposed. Asbestosis among household members of asbestos factory workers was first described in the 1970s [18]. More recently, Kilburn et al. $[17,19]$ found a high prevalence of asbestosis and other asbestos-related diseases in the families of shipyard workers.

The third patient described here was also from Casale Monferrato. He presented bilateral pleural plaques, and monolateral pleural effusion with peripheral round atelectasis. In exposed subjects, benign pleural effusion may occur early (within 10 years, unlike other asbestos-related diseases) or (as in the case presented) later in life, in association with long-standing pleural plaques [20, 21]. Rounded atelectasis (also known as folded lung, pleuroma or Blesovsky's syndrome) is the entrapment of a peripheral part of the lung by infolding of the adjacent thickened pleura $[4,22]$. On computed tomography scans (figure 4), the characteristic image is a peripherally sited mass, pleural thickening, and the curved swirl of the vessels and bronchi converging on the pulmonary hilum (the "comet tail" sign) [23]. This sign allows a differentiation between rounded atelectasis and a neoplasm, making further invasive diagnostic procedures unnecessary in most cases. Apparently, rounded atelectasis deriving from residential asbestos exposure has not been reported before.

The diagnosis of respiratory disease due to non-occupational asbestos exposure imposes a duty to inform the patient of the environmental origin of his/her illness (and therefore of the possibility of obtaining legal compensation), as well as of the risk of progression of disease, the risk of malignancy, and especially the interaction between smoking and asbestos exposure in enhancing the risk of lung cancer. Further exposure to asbestos or other environmental/occupational carcinogens should be avoided where possible. Immunsation 
against pneumococcal pneumonia and influenza is advised [1, 5].

In conclusion, the cases reported here indicate that non-neoplastic asbestos-related diseases such as asbestosis, rounded atelectasis and benign pleural effusion, which are usually observed as a consequence of occupational exposures, may also be encountered, albeit rarely, in subjects living in contaminated geographical areas and houses. In such cases, careful environmental anamnesis, radiology (conventional chest radiography with ILO classification and computed tomography), and the search for asbestos fibres by BAL, are helpful in differentiating diagnosis from other malignant and nonmalignant respiratory diseases. The correct diagnosis, in turn, is important for adequate patient management in the light of the risks of progression of the disease and malignancy, and in relation to medico-legal issues.

Acknowledgments: We would like to thank Dr. Alberto Suppi and Dr. Marco Fiori for radioimaging and helpful discussion. The microphoto shown in figure 3 is by Dr. Antonio Massola.

\section{References}

1. Isidro Montes I, Abu Shams K, Alday E, et al. Guidelines on asbestos-related pleuropulmonary disease. Arch Bronconeumol 2005; 41: 153-168.

2. Dodson RF, Hammar SP, eds. Asbestos. Risk assessment, epidemiology and health effects. Boca Raton, FL: Taylor \& Francis, 2006.

3. Castleman BI, Joshi TK. The global asbestos struggle today. Eur J Oncol 2007; 12: 149-154.

4. Cugell DW, Kamp DW. Asbestos and the pleura. A review. Chest 2004; 125: 1103-1117.

5. Guidotti TL, Miller A, Christiani D, et al. American Thoracic Society documents. Diagnosis and initial management of nonmalignant diseases related to asbestos. Am J Crit Care Med 2004; 170: 691-715.

6. Hillerdal G. Pleural plaques: incidence and epidemiology, exposed workers and the general population. Indoor Built Environ 1997; 6: 86-95.

7. Metintas M, Metintas S, Hillerdal G, et al. Nonmalignant pleural lesions due to environmental exposure to asbestos: a field-based, cross-sectional study. Eur Respir J 2005; 26: 875-880.

8. Peipins LA, Lewin M, Campolucci S, et al. Radiographic abnormalities and exposure to asbestos-conta- minated vermiculite in the community of Libby, Montana, USA. Environ Health Perspect 2003; 111: 17531759.

9. Magnani C, Terracini B, Ivaldi C, Mancini A, Botta M. [Tumor mortality and from other causes in asbestos cement workers at the Casale Monferrato plant]. Med Lav 1996; 87: 133-146.

10. Marconi A, Cecchetti G, Barbieri M. Airborne mineral fibre concentrations in an urban area near an asbestoscement plant. IARC Sci Publ 1989; 90: 336-346.

11. International Labour Office. International classification of radiographs of pneumoconiosis. Geneva, Seitzerland: International Labour Organization, 2003.

12. Amendola P, Belli S, Binazzi A, et al. [Mortality from malignant pleural neoplasms in Broni (Pavia), 19801997]. Epidemiol Prev 2003; 27: 86-90.

13. Magnani C, Terracini B, Ivaldi C, et al. A cohort study on mortality among wives of workers in the asbestos cement industry in Casale Monferrato, Italy. $\mathrm{Br} J$ Ind Med 1993; 50: 779-784.

14. Magnani C, Terracini B, Ivaldi C, Botta M, Mancini A, Andrion A. Pleural malignant mesothelioma and nonoccupational exposure to asbestos in Casale monferrato, Italy. Occup Environ Med 1995; 52: 362-367.

15. Ferrante D, Bertolotti M, Todesco A, Mirabelli D, Terracini B, Magnani C. Cancer mortality and incidence of mesothelioma in a cohort of wives of asbestos workers in Casale Monferrato, Italy. Environ Health Perspect 2007; 115: 1401-1405.

16. Magnani C, Mollo F, Paoletti L, et al. Asbestos lung burden and asbestosis after occupational and environmental exposure in an asbestos cement manufacturing area: a necroscopy study. Occup Environ Med 1998; 55: 840-846.

17. Kilburn KH, Lilis R, Anderson HA, et al. Asbestos disease in family contacts of shipyard workers. Am J Public Health 1985; 75: 615-617.

18. Anderson H, Lilis R, Daum S, Selikoff IJ. Asbestosis among household contacts of asbestos factory workers. Ann NY Acad Sci 1979; 330: 387-399.

19. Kilburn KH, Warshaw R, Thornton JC. Asbestos diseases and pulmonary symptoms and signs in shipyard workers and their families in Los Angeles. Arch Int Med 1988; 146: 2213-2220.

20. Robinson BWS, Musk AW. Benign asbestos pleural effusion: diagnosis and course. Thorax 1981; 36: 896-900.

21. Hillerdal G, Ozesmi M. Benign asbestos pleural effusion: 73 exudates in 60 patients. Eur J Respir Dis 1987; 71: 113-121.

22. Blesovsky A. The folded lung. Br J Dis Chest 1966; 60: 19-22.

23. Gamsu G, Aberle DR, Lynch D. Computed tomography in the diagnosis of asbestos-related thoracic disease. $J$ Thorac Imaging 1989; 4: 61-67. 